\title{
Predicting Success In Nursing Programs
}

\author{
Suzanne J. Crouch, Chamberlain College of Nursing, USA
}

\begin{abstract}
The purpose of this study was to assess the merit of the Watson -Glaser Critical Thinking Appraisal as a pre-admission criterion in conjunction with the frequently utilized admission criteria of the college prerequisite grade point average and the National League of Nursing preadmission test.

Data were collected from 192 first-year nursing students. A discriminant analysis was computed to determine the significance of the prediction formula. The predictor variables of prerequisite grade point average, National League for Nursing pre-admission test score, and the WatsonGlaser Critical Thinking Appraisal score were significant in predicting success in a nursing program as measured by the dependent variable nursing grade point average. The prediction formula, as a whole, had a significance level of $\underline{\underline{p}} \leq .001$. The identification and validation of applicant selection criteria that predict success in the nursing programs will continue to be of significant importance because of emphasis on the importance of fostering critical thinking in nursing education (National League for Nursing Accrediting Commission, Inc., 2012).
\end{abstract}

Keywords: Predicting Success In Nursing; Critical Thinking; Watson -Glaser Critical Thinking Appraisal

\section{INTRODUCTION}

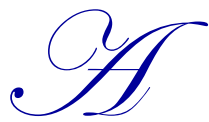

dmission criteria for the selection of students are determined by educational institutions. Presently, no objective instrument is currently recognized as the sole predictor of successful nursing program completion (Seago, J., Keane, D., Chen, E., Spetz, J., \& Grumbach, K., 2012). If successful program completion could be predicted from testing prior to entry, measures could be introduced to guide admission procedures. In addition, entering students could receive counseling regarding their potential for successful completion of the nursing program.

A variety of admission criteria exists, often including grade point average, pre-admission tests, and Scholastic Aptitude tests. The above-listed criteria are representative of the cognitive domain. Literature documents that cognitive domain predictors have been shown to correlate with continuing academic achievement (Wolkowitz, A., \& Kelley, J. 2010). Understanding the factors that predict successful attainment of registered nurse status would benefit students, the faculty who advise them, and health care consumers for whom they provide care.

With the rapidly evolving healthcare system, the role of the registered nurse has expanded considerably. Registered nurses have major roles in health promotion, illness prevention, and the care of patients with acute and chronic illness. Nurses must be able to collect pertinent and appropriate data, distinguish among several points of view, and evaluate multiple lines of reasoning. Thinking critically is necessary in a practice discipline where individuals are faced with making life and death decisions daily. Nursing students must be able to develop and use critical thinking abilities to render safe, effective patient care. The complexity of medical technology mandates the need for nurses who are clinically competent and can think critically. One required outcome that school faculties must address in the accreditation process is demonstrating that students can think critically. Nursing school faculties are to provide their own definitions of critical thinking, set their own standards, measure outcomes in a manner consistent with their definitions, and demonstrate how they used the information gained in the process to revise the nursing curriculum (National League for Nursing Accrediting Commission, Inc., 2012). 
The Watson-Glaser Critical Thinking Appraisal has been used to measure critical thinking among different levels of nursing students and educators and to examine correlations between critical thinking and variables such as clinical judgment, successful completion of the nursing program, and performance on the National Council Licensure Examination.

Over the years, critical thinking has emerged as a widely discussed concept among the nursing education literature (Leleux, A., 2012; Romeo, E., 2010; Giddens \& Gloeckner, 2005, Gross, Takazawa, \& Rose, 1987; Jones, 1991; Miller, 1992; Rane-Szostak, 1996). It is the responsibility of nurse educators to ensure that nursing graduates have developed the critical thinking abilities necessary to practice the profession of nursing. The demonstration of critical thinking in the clinical setting is a universally expected behavior of professional nurses engaged in practice (Giddens \& Gloeckner, 2005). While the Watson-Glaser Critical Thinking Appraisal has been widely used to predict success in professions in which critical thinking plays a key role, few studies have been conducted in the profession of nursing using the Watson-Glaser Critical Thinking Appraisal as a predictor of successful completion of the nursing program. None of the studies listed above utilized the prediction formula in which the independent variable was the nursing grade point average and the dependent variables were the college prerequisite grade point average, the Watson-Glaser Critical Thinking Appraisal score, and National League for Nursing test score.

\section{Purpose Of The Study}

The purpose of this study was to assess the merit of the Watson-Glaser Critical Thinking Appraisal as a pre-admission criterion along with frequently utilized admission criteria of the college prerequisite grade point average and the National League for Nursing pre-admission test to predict success in nursing programs.

The predictor variables that were investigated are the Watson-Glaser Critical Thinking Appraisal test score, the college prerequisite grade point average, and the National League for Nursing pre-admission test scores. The criterion variable is the nursing grade point average.

The study sought answers to the following questions:

1. Is there a significant relationship between Watson-Glaser Critical Thinking Appraisal test scores and nursing grade point averages?

2. Is there a significant relationship between college prerequisite grade point averages and nursing grade point averages?

3. Is there a significant relationship between National League for Nursing pre-admission test scores and nursing grade point averages?

4. Are the predictor variables of college prerequisite grade point average, National League for Nursing preadmission test score, and the Watson-Glaser Critical Thinking Appraisal score significant in predicting success in nursing programs as measured by the dependent variable nursing grade point average?

\section{Significance Of The Problem}

The identification and validation of applicant selection criteria that predict success in the nursing program is of significant importance to the students, the educational institution, and the community (Seago, J., Keane, D., Chen, E., Spetz, J., \& Grumbach, K., 2012). Student nurses who enter nursing programs but fail to successfully complete them represent a considerable loss in the healthcare industry that directly impacts society.

Secondly, the ability to foster the development of critical thinking skills in preparation for nursing practice is emphasized in the NLN criteria for accreditation (National League for Nursing Accrediting Commission, Inc., 2012). The National League for Nursing identified critical thinking as a major required outcome (National League for Nursing Accrediting Commission, Inc., 2012). Outcome criteria that are student-oriented were added to the National League for Nursing accreditation process. Accredited schools of nursing are now required to demonstrate that students can think critically (National League for Nursing Accrediting Commission, Inc., 2012). Nursing educators are required to demonstrate that students are developing specific critical thinking skills including analysis, 
reasoning, decision-making and independent judgment relevant to the discipline of nursing (Giddens \& Gloeckner, 2005).

If success can be predicted through the use of objective instruments prior to entry into the nursing program, the student would be afforded the opportunity of having a reasonable estimate of their potential for successful completion of the nursing program. Students who are entering the nursing program deserve a reasonable estimate of the likelihood for successful program completion. In addition, students who may be at high risk for failure to complete the program could be identified early and assisted.

In nursing programs around the country, a major paradigm shift has occurred. The focus of nursing education has changed from a curricular content to curricular outcome, with a major emphasis on helping students to think critically. The nursing curriculum is expected to contribute positively to critical thinking ability. It is imperative that there be quantitative measures to evaluate whether these skills are being developed. This objective can be achieved by the utilization of currently developed critical thinking assessment tools or by the development of a nurse-based critical thinking assessment tool. For the purpose of this study, the Watson-Glaser Critical Thinking Appraisal was utilized for measuring critical thinking in nursing students.

\section{LIMITATIONS}

1. The study sample was from only one institution and therefore the findings may not be generalizable.

2. Three independent variables were tested in this study for the purpose of predicting success in nursing programs. Other predictor variables outside the focus of this study were not explored.

3. The Watson-Glaser Critical Thinking Appraisal has been reported to predict success in instructional programs in which critical thinking plays a key role (Watson and Glaser, 1964). It is unclear, however, the degree to which critical thinking impacts the role of the registered nurse compared to other professions.

4. Finally, another limitation resulted from the use of a voluntary sample. This introduced the possibility of bias and inhibits generalizing the findings of this study to the total population of nursing students.

\section{Population And Sample}

To test the hypotheses, data for the study were obtained from the admission files of freshman nursing students enrolled at a college in southeastern Florida. The nursing program has received accreditation from the National League for Nursing. Data from these records revealed National League for Nursing pre-admission test scores as well as the college prerequisite grade point averages. Additionally, data were generated from the WatsonGlaser Critical Thinking Appraisal that was administered to all nursing students entering the program.

From a population of 200 freshman nursing students, the study sample consisted of 192 who were willing to participate. All students who participated in the study were enrolled in the nursing program on a full-time basis.

\section{Instrumentation}

The Watson-Glaser Critical Thinking Appraisal (WGCTA) was utilized to measure critical thinking ability. The WGCTA provides an estimate on an individual's critical thinking ability by means of five subtests. In addition to recognizing that the questions in the Watson-Glaser Critical Thinking Appraisal represent sufficient samples of the five abilities stated above, Watson and Glaser (1964) report that the Critical Thinking Appraisal can predict success in instructional programs as well as in professions in which critical thinking plays a key role. The reliability and validity of the Watson-Glaser Critical Thinking Appraisal have been set forth in the Watson \& Glaser Manual (Watson \& Glaser, 1980). Assessment of reliability included estimates of internal consistency, stability of test scores over time, and the correlation between scores on alternate forms. Split-half reliability coefficients ranged from .69 to .85. Means and standard deviations were found to be almost identical when the Watson-Glaser Critical Thinking Appraisal was administered to the same sample twice over a period of three months. Reasonable stability of the measure over time was reflected in a coefficient of .73. Alternate form reliability was calculated by correlating responses of subjects who took Forms A and B $(r=.75)$. Means and standard deviations were equivalent for both A and $\mathrm{B}$ forms. 
Construct validity has been determined through utilization of the Watson-Glaser Critical Thinking Appraisal in educational settings designed to improve critical thinking. In addition, a comparison of the WatsonGlaser Critical Thinking Appraisal and other mental ability and comprehensive tests was completed (Watson and Glaser, 1964).

\section{Procedure}

The Watson-Glaser Critical Thinking Appraisal was administered to all nursing students upon entrance into the nursing program. The Watson-Glaser Critical Thinking Appraisal consisted of 80 items and took approximately one hour to administer. All subjects volunteered to participate in the study. Students' records were examined and the college prerequisite grade point averages and the National League for Nursing pre-admission test scores were recorded. After completion of the nursing program, nursing grade point averages for all nursing courses were computed.

\section{STATISTICAL ANALYSES}

The Statistical Package for the Social Sciences was used to analyze the data. Analysis involved the use of several statistical procedures. A Pearson correlation was computed to determine if there was a significant relationship among the independent variables - college prerequisite grade point average, National League for Nursing pre-admission test, and Watson-Glaser Critical Thinking Appraisal, with the dependent variable - nursing grade point average. Descriptive statistics were computed for each of the variables.

A discriminant analysis was computed to determine if the overall prediction formula was significant. The mean, standard deviation, variance and range were computed for each of the independent variables as well as the dependent variable.

A one-way ANOVA was computed to determine differences in nursing grade point averages within the groups and between the groups. Post hoc tests included Tukey and Scheffe. These tests identified if the performance as measured by the nursing grade point average differed for students according to groups.

The college prerequisite grade point average and the nursing grade point average are based on a 4.0 scale. The National League for Nursing pre-admission test scores are listed as raw scores out of a possible 100. The Watson-Glaser Critical Thinking Appraisal scores are listed as raw scores out of a possible 80.

The mean for the dependent variable - nursing grade point average - was 2.82 . The standard deviation was .439 , the variance was .19 , and the range was 2.0. The college prerequisite grade point average mean was 2.97 . The standard deviation was .476, the variance was .22, and the range was 2.65 . The National League for Nursing preadmission test score mean was 84.09 . The standard deviation was 10.93 , the variance was 119.52 , and the range was 51.

The mean for the Watson-Glaser Critical Thinking Appraisal pre-test was 55.41. The standard deviation was 8.25 , and the range was 4.3 (see Table 1).

Table 1: Descriptive Statistics

\begin{tabular}{|l|c|c|c|}
\hline \multicolumn{1}{|c|}{ Variable } & Mean & Std. Deviation & N \\
\hline Nursing GPA After Completion Of Program & 2.82 & .44 & 192 \\
\hline Watson-Glaser Critical Thinking & 55.41 & 8.25 & 192 \\
Appraisal Score Before Entering Program & 2.97 & .47 & 192 \\
\hline Prerequisite GPA & 84.09 & 10.93 & 192 \\
\hline NLN Entrance Score In Percentile Form & & \\
\hline
\end{tabular}

The Pearson correlation revealed a significant relationship between Watson-Glaser Critical Thinking Appraisal pre-test scores and the nursing grade point average. The result of the Pearson correlation for 192 subjects was $r=.255 ; \underline{p} \leq .001$ (see Table 2). 
Table 2: Dependent And Independent Variable Correlations

\begin{tabular}{|c|c|c|c|c|c|}
\hline $\begin{array}{c}\text { Pearson Correlation } \\
\text { Sig. (1-tailed) }\end{array}$ & $\begin{array}{c}\text { Nursing GPA After } \\
\text { Successful Completion Of Program }\end{array}$ & 1.000 & $\begin{array}{c}.255 \\
(p \leq .001)\end{array}$ & $\begin{array}{c}.376 \\
(\underline{p} \leq .001) \\
\end{array}$ & $\begin{array}{c}.293 \\
(p \leq .001)\end{array}$ \\
\hline & $\begin{array}{l}\text { Watson-Glaser Critical Thinking Appraisal } \\
\text { score, Part A, before entering program }\end{array}$ & $\begin{array}{c}.255 \\
(p \leq .001) \\
\end{array}$ & 1.000 & $\begin{array}{c}.208 \\
(\underline{p} \leq .01) \\
\end{array}$ & $\begin{array}{c}.447 \\
(\underline{p} \leq .001) \\
\end{array}$ \\
\hline & Prerequisite GPA & $\begin{array}{c}.376 \\
(p \leq .001)\end{array}$ & $\begin{array}{c}.208 \\
(p \leq .01)\end{array}$ & 1.000 & $\begin{array}{c}.282 \\
(p \leq .001)\end{array}$ \\
\hline & NLN entrance score in percentile form & $\begin{array}{c}.293 \\
(\underline{p} \leq .001)\end{array}$ & $\begin{array}{c}.447 \\
(p \leq .001)\end{array}$ & $\begin{array}{c}.282 \\
(\underline{p} \leq .001)\end{array}$ & 1.000 \\
\hline
\end{tabular}

$\mathrm{N}=192$

Pearson correlation revealed a significant relationship between college prerequisite grade point average and the dependent variable - nursing grade point average. The result of the Pearson correlation for 192 subjects was $r=$ $.376 ; \underline{p} \leq .001$ (see Table 2).

Pearson correlation revealed a significant relationship between the National League for Nursing preadmission test scores and the dependent variable - nursing grade point average. The result of the Pearson correlation for 192 subjects was $r=.293 ; \underline{p} \leq .001$ (see Table 2).

The fourth hypothesis proposed that a student's nursing grade point average cannot be predicted by the prediction equation of the Watson-Glaser Critical Thinking Appraisal, the college prerequisite grade point average and the National League for Nursing pre-admission test score. Discriminant analysis and a one-way ANOVA with post hoc Scheffe and Tukey tests were used to test the hypothesis. In addition, descriptive statistics, including the mean, standard deviation, variance, and range, were computed for each of the variables.

The research hypothesis was rejected. Discriminant analysis revealed that the overall prediction formula $\mathrm{Y}_{1}$ $=c+b_{1} X_{1}+b_{2} X_{2}+b_{3} X_{3}$ is significant. $(F=14.847 ; d f=191 ; \underline{p} \leq .001$ (see Tables 3 and 4$)$.

Table 3: Analysis Of Variance Among Variables

\begin{tabular}{|l|c|c|c|c|c|}
\hline Model & Sum of Squares & df & Mean Square & F & Sig. \\
\hline 1 Regression & 70802.521 & 3 & 23600.840 & 14.847 & .001 \\
\hline Residual & 298847.848 & 188 & 1589.616 & & \\
\hline Total & 369650.370 & 191 & & & \\
\end{tabular}

Predictors: (Constant), NLN entrance score in percentile form, prerequisite GPA, Watson-Glaser Critical Thinking Appraisal score. Dependent Variable: Nursing GPA after successful completion of program.

Table 3: Analysis Of Variance Among Variables (Continued)

\begin{tabular}{|l|c|c|c|c|c|}
\hline Model & Unstandardized Coefficients & \multicolumn{3}{|c|}{ Standardized Coefficients } \\
\hline & B & Std. Error & Beta & t & Sig. \\
\hline 1 (Constant) & 109.803 & 27.210 & & 4.035 & .001 \\
\hline $\begin{array}{l}\text { Watson-Glaser Thinking } \\
\text { Appraisal Score }\end{array}$ & .660 & .393 & .124 & 1.680 & .095 \\
\hline Prerequisite GPA & .284 & .063 & .308 & 4.478 & .001 \\
\hline $\begin{array}{l}\text { NLN Entrance Score In } \\
\text { Percentile Form }\end{array}$ & .608 & .302 & .151 & 2.014 & .045 \\
\hline
\end{tabular}

\begin{tabular}{|l|c|c|c|c|c|}
\hline \multicolumn{7}{|c|}{ Change Statistics } \\
\hline Model & R Square Change & F Change & df1 & df2 & Sig. F Change \\
\hline 1 & .192 & 14.847 & 3 & 188 & .001 \\
\hline
\end{tabular}

Predictors: (Constant), NLN entrance score in percentile form, prerequisite GPA, Watson-Glaser Critical Thinking Appraisal score 
Predicted group membership, according to identified categories, is illustrated in Classification Results (Table 4). The categories were delineated as follows:

2.0-2.49 Marginally successful

2.5-2.99 Somewhat successful

3.0-3.49 Significantly successful

3.5-4.0 Extremely successful

Table 4: Classification Results ${ }^{\mathrm{a}}$



a 40.1 percent of original group cases correctly classified

Discriminant analyses revealed that 40.1 percent of original grouped cases correctly classified. The Scheffe test was computed to identify if performance, as measured by the nursing grade point average, would differ for students who were ranked in the following groups according to their college prerequisite grade point average.

$\begin{array}{lll}\text { Group } 0 & \text { GPA of less than } 1.9 & \text { Not successful } \\ \text { Group 1 } & 2.0-2.49 & \text { Marginally successful } \\ \text { Group 2 } & 2.50-2.9 & \text { Noticeably successful } \\ \text { Group 3 } & 3.0-3.49 & \text { Markedly successful } \\ \text { Group 4 } & 3.5-4.0 & \text { Extremely successful }\end{array}$

The Scheffe test was computed to identify if group 4 would perform better than group 3, who performs better than group 2 , who performs better than group 1 .

The Scheffe test indicated that group 4 performed significantly higher than groups 3,2 , and $1(\underline{p} \leq .01 ; \underline{p} \leq$ $.001, \underline{p} \leq .001)$. However, group 3 did not perform significantly higher than group 2 or $1(\underline{p}=.765 ; \underline{p}=.128)$ and group 2 did not perform significantly higher than group $1(\underline{p}=.647)$ (see Table 5). 
Table 5: Scheffe Test For Differences In Predicted Classifications

\begin{tabular}{|l|c|c|c|c|}
\hline \multirow{4}{*}{1.99 or below } & $2.0-2.49$ & 12.57 & 29.834 & .996 \\
& $2.5-2.99$ & -1.80 & 29.357 & 1.000 \\
& $3.0-3.49$ & -11.61 & 29.315 & .997 \\
& $3.5-4.0$ & -44.38 & 29.776 & .695 \\
\hline \multirow{5}{*}{$2.0-2.49$} & 1.99 or below & -12.57 & 29.834 & .996 \\
& $2.5-2.99$ & -14.37 & 9.110 & .647 \\
& $3.0-3.49$ & -24.18 & 8.974 & .128 \\
& $3.5-4.0$ & -56.94 & 10.382 & .001 \\
\hline \multirow{5}{*}{$3.5-2.99$} & 1.99 or below & 1.80 & 29.357 & .647 \\
& $2.0-2.49$ & 14.37 & 9.110 & .765 \\
& $3.0-3.49$ & -9.81 & 7.230 & .001 \\
\hline 3.49 & $3.5-4.0$ & -42.57 & 8.917 & .997 \\
& 1.99 or below & 11.61 & 29.315 & .128 \\
& $2.0-2.49$ & 24.18 & 8.974 & .765 \\
& $2.5-2.99$ & 9.81 & 7.230 & .009 \\
\hline
\end{tabular}

\section{CONCLUSIONS}

Findings of the study indicated a significant relationship between the nursing grade point average and the Watson-Glaser Critical Thinking Appraisal score, $r=.255 ; p \leq .001$. Findings of this study also determined a significant relationship between nursing grade point average and college prerequisite grade point average, $r=.376$; $\underline{p} \leq .001$. Results of this study indicated a significant relationship between nursing grade point average and the National League for Nursing pre-admission test scores, $r=.293 ; \underline{p} \leq .001$.

The data analysis in this study revealed a significant overall prediction formula in which the dependent variable was the nursing grade point average and the independent variables were the Watson-Glaser Critical Thinking Appraisal, the college prerequisite grade point average, and the National League for Nursing preadmission test score $(\mathrm{F}=14.847 ; \mathrm{df}=191 ; \underline{\underline{ }} \leq .001)$.

The predictor variables of college prerequisite grade point average, National League for Nursing preadmission test score, and the Watson-Glaser Critical Thinking Appraisal pre-test score were significant in predicting success in the associate degree nursing program, as measured by the dependent variable nursing grade point average. The prediction formula, as a whole, had a significance level of $\underline{p} \leq .001$. The results of this study suggest that the Watson-Glaser Critical Thinking Appraisal appears to be a useful predictor of successful nursing program completion.

Research attempting to answer questions regarding factors that predict success in nursing programs may represent a fundamental contribution to both recruitment and retention of students. In order to meet the health care needs of our aging population, there must be an adequate supply of registered nurses. Students who may be at high risk for failure to complete the nursing program could be identified early and assisted. The assessment of nursing students' critical thinking abilities is particularly important as professional nurses encounter more acutely ill patients, increasing technology, and complex ethical issues. It is vital to determine if student nurses possess critical thinking abilities and if those abilities become more sophisticated as they advance through their educational program.

\section{RECOMMENDATIONS}

1. A valid and reliable instrument to measure critical thinking, as it relates specifically to the discipline of nursing, should be developed by nursing educators. 
2. Central to all critical thinking programs is training for educators and assistance in the selection of teaching strategies that encourage critical thinking.

3. Nursing faculty need to be provided with the opportunity to develop critical thinking abilities in themselves by exposure to both the theory of critical thinking as well as experiencing the implementation of methodologies.

4. Nursing students need to be active participants in their own learning experiences. This could include the use of the nursing laboratory with patient care simulators that would allow them to explore creative plans of care without jeopardizing the patients' well-being.

5. Another form of performance assessment is the growing area of video or computer simulations. Important advantages include consistency of conditions and criteria and the opportunity to assess students in potentially unpredictable situations.

\section{RECOMMENDATIONS FOR FURTHER RESEARCH}

1. This study investigated a prediction formula for success in nursing programs. The predictor variables that were studied included the Watson-Glaser Critical Thinking Appraisal, the National League for Nursing preadmission test, and the college prerequisite grade point average. More reliable data might be obtained by implementing a study to first test the significance of the existing admission criteria. The third independent variable - Watson-Glaser Critical Thinking Appraisal scores - could then be added to the prediction equation. This would provide important information to compare the significance of the two prediction formulas.

2. A replication of this study should be conducted with a larger non-convenience sample from a variety of nursing programs.

3. Additional research should be conducted to identify teaching strategies that encourage critical thinking in nursing students.

4. Studies to determine how nursing educators score on the Watson-Glaser Critical Thinking Appraisal would provide data regarding the critical thinking abilities of educators.

5. Additional research should be conducted to determine if there is a relationship between the critical thinking abilities of nursing faculty and their students.

6. Critical thinking is an accreditation requirement for nursing programs. A study reviewing National League of Nursing nationwide accreditation reports to identify which objective instrument is used most frequently to measure critical thinking in nursing programs would be of interest.

7. Follow-up studies to test the critical thinking abilities of graduate nursing students following their first, second and third years of employment as a registered nurse may prove interesting.

In conclusion, a formula for predicting success in nursing programs utilizing the Watson-Glaser Critical Thinking Appraisal test, the college prerequisite grade point average, and the National League for Nursing preadmission test score was tested. The predictor variables of college prerequisite grade point average, National League for Nursing pre-admission test score, and the Watson-Glaser Critical Thinking Appraisal score were significant in predicting success in the nursing program, as measured by the dependent variable nursing grade point average. The prediction formula, as a whole, had a significance level of $\underline{x} \leq .001$.

Further research designed to investigate possible predictors of success, such as grade point average, SAT, ACT, previous college credits, critical thinking, and National League for Nursing pre-admission tests, should be conducted. The identification and validation of applicant selection criteria that predict success in the nursing programs will continue to be of significant importance because of emphasis on the importance of fostering critical thinking in nursing education (National League for Nursing Accrediting Commission, Inc., 2012).

\section{AUTHOR INFORMATION}

Suzanne Crouch has been a nurse for thirty-eight years and a nurse educator for twenty-seven years. Her nursing career began after graduating from Wright State University with a BSN in 1976. She received her MS in nursing in 1990 followed by a doctorate in education from Florida Atlantic University in 1999. Suzanne is an Advanced Registered Nurse Practitioner and is board certified in Adult Psychiatric/Mental Health Nursing. She is actively 
involved in nursing research and has publications in the areas of Maternal-Child Nursing, Nursing Education, Nursing Leadership, and the Acute Care Environment. Email: scrouch@ chamberlain.edu.

\section{REFERENCES}

1. Giddens, J., \& Gloeckner, G. (2005). The relationship of critical thinking to performance on the NCLEXRN. Journal of Nursing Education. 44(2). 85-89.

2. Gross, Y. T., Takazawa, E. S., \& Rose, C. L. (1987). Critical thinking and nursing education. Journal of Nursing Education 26, 317-323.

3. Jones, S. (1991). Critical thinking: impact on nursing education. Journal of Advanced Nursing 16(5), 529533.

4. Leleux, A. (2012). Let's get critical! "A critical look at critical thinking" Nursing Management, August 2012. Nursing Management, 43(12), 8.

5. Miller, M. (1992). Outcomes evaluation: measuring critical thinking. Journal of Advanced Nursing 17 (14), 67-73.

6. National League for Nursing Accrediting Commission, Inc. (2012). Accreditation manual. Retrieved November 8, 2013, from http://www.healthforceminnesota.org/Resources/documents/NLNACManual2008UpdatedJune2012.pdf.

7. Rane-Szostak, D. (1996). Issues in measuring critical thinking: Meeting the challenge. Journal of Nursing $35(1), 5-11$.

8. Romeo, E. (2010). The Predictive Ability of Critical Thinking, Nursing GPA and SAT Scores On FirstTime NCLEX-RN (RTM) Performance.

9. Seago, J., Keane, D., Chen, E., Spetz, J., \& Grumbach, K. (2012). Predictors of students' success in community college nursing programs. The Journal Of Nursing Education, 51(9), 489-495.

10. Watson, G., \& Glaser, E. M. (1980). Manual: Watson-Glaser Critical Thinking Appraisal. Cleveland, OH: Psychological Corporation.

11. Watson, G., \& Glaser, E. (1964). Watson-Glaser Critical Thinking Manual. New York: Harcourt Brace Jovanovich, Inc.

12. Wolkowitz, A., \& Kelley, J. (2010). Academic predictors of success in a nursing program. The Journal Of Nursing Education, 49(9), 498-503. 
NOTES 